\section{Recoil Effects of Neutron Reactions in Sodium Bromate}

THE chemical effects following radioactive neutron capture and isomeric transition of the nuclei of bromine atoms in bromates have been studied by a number of investigators. ${ }^{1}$. The present communication describes our investigation of the ohemical distribution of radioactive bromine atoms arising from ${ }^{79} \mathrm{Br}(n, 2 n)^{78} \mathrm{Br}$ and ${ }^{79} \mathrm{Br}(n, \gamma)^{80}$ $\mathrm{Br}$ reactions in crystalline sodium bromate. The effects of the irradiation and dissolution temperatures were investigated and the recoil effects of both nuclear reactions were compared.

Powdered sodium bromate was irradiated with fast neutrons produced by the ${ }^{8} \mathrm{H}(d, n)^{4} \mathrm{He}$ reaction, or with slow neutrons moderatod in paraffin blocks. The irradiated salt was dissolved in water and the bromine species of lower oxidation states were separated from bromate by extraction with carbon totrachloride containing a small amount of molecular bromine, or by precipitation of bromide as silver bromide. The radioactivity of ${ }^{78} \mathrm{Br}$ (halflife, $6.4 \mathrm{~min}$ ) or ${ }^{80} \mathrm{Br}$ (half-lifo, $18 \mathrm{~min}$ ) was measured by means of a Geiger - Müller counter or an NaI scintillation counter.

The results are summarized in Table 1 . The mean values of repeated determinations are shown together with the standard deviations.

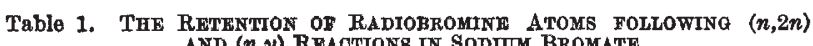

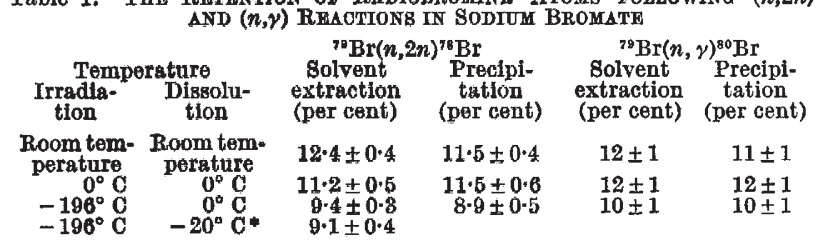

- Dissolved in a eutectic mixture of llthium chloride and water.

The retention values of ${ }^{80 \mathrm{~m}} \mathrm{Br}$ and ${ }^{82} \mathrm{Br}$ in slow neutron irradiation of solid sodium bromate have been reported by several authors ${ }^{2-6}$. The results range from 4 to 25 per cent depending on the conditions of irradiation and separation, Jach and Harbottle reported that, when alkali bromate was irradiated at dry-ice temperature, nearly the same retention values were obtained for ${ }^{80} \mathrm{~m} \mathrm{Br}$ and ${ }^{82} \mathrm{Br}$ recoil atoms from $(n, \gamma)$ reactions, whereas an isotopic effect appeared as the irradiated salts were annealed at $200^{\circ} \mathrm{C}$. Our results for ${ }^{80} \mathrm{Br}$ are in good agreement with the initial retention values for ${ }^{80 m} \mathrm{Br}$ and ${ }^{\text {s }} \mathrm{Br}$ obtained by them.

Although it is generally observed that the retention is sensitive to irradiation and dissolution temperatures, our attempts at low-temperature irradiation and dissolution resulted in no marked decrease of the retention values. This confirms the results reported by previous workers in the case of ${ }^{80 \mathrm{~m}} \mathrm{Br}$ and ${ }^{\mathrm{B}} \mathrm{Br}$ recoil atoms from $(n, \gamma)$ reactions in potassium bromate?

Comparison of recoil effects in $(n, \gamma)$ and $(n, 2 n)$ re. actions has been attompted by several investigators. In all alkyl iodides that have ever been investigated almost the same retention values have been reported for both reactions ${ }^{8,9}$. On the other hand, different retention values have been observed in propyl bromides 10 , molecular iodine dissolved in various hydrocarbons ${ }^{11}$, and cobalt complexes ${ }^{12}$. In sodium bromoacotate, the retention of ${ }^{80} \mathrm{mBr}$ atoms in $(n, 2 n)$ reaction has been found to be very similar to that of ${ }^{82} \mathrm{Br}$ atoms in $(n, \gamma)$ reaction, whereas ${ }^{80} \mathrm{mBr}$ atoms arising from $(n, \gamma)$ reaction have showed somewhat different retention values ${ }^{13}$. Larger recoil energy involved in the $(n, 2 n)$ reactions and the annealing effect of recoil protons have been suggested as the possible cause of such differences.

The data presented in this communication indicate that in sodium bromate there exists no difference, within experi- mental errors, between the retentions for both reactions. Although no theoretical or experimental estimate of the recoil energy of $(n, 2 n)$ reactions is as yet available, it would be reasonable to presume that the incident fast neutron or the outgoing two neutrons impart far larger recoil energy to the atom than the capture $\gamma$-quanta emitted in $(n, \gamma)$ reactions. It is noteworthy in an experimental estimate of recoil mechanism that in certain compounds, such as alkyl iodides and sodium bromate, the retention seems to remain unaffected by a large change in recoil energy.

Further work is in progress on other bromates.

Nobufusa SaIto

Fumitoshi Ambe

Hirotoshi SaNo

Department of Chemistry,

Faculty of Science,

University of Tokyo.

1 See, for example: Apers, D. J., Dejehet, F. G., van Outryve d'Ydewalle, B. S., Capron, P. C., Jach, J., and Moorhead, E., Radiochim. Acta, 1, 193 (1963).

${ }^{2}$ Libby, W. F., J. Amer. Chem. Soc, 62, 1930 (1940).

s Berne, E., J. Chem. Soc., S838 (1949).

- Jach, J., and Harbottle, G., Trans. Farad. Soc., 54, 520 (1958).

"Saito, N., Tomita, I,, and Furukawa, M.. J., Atomic Energy Soc., Japan Campbell, I. G. J. Chim. Phys. 56, 665 (1959).

"Veljkovie, S., and Harbottle, G., Nature, 191, 1287 (1961).

- Sohuler, R. H., J. Chem. Phys., 22, 2026 (1054). - MoCauley, C. E., Hilsdorf, G. J, Geissler, P. R., and Schuler, R. H.,
J. Amer. Chem. Soc., 78, 3246 (1956).

${ }^{20}$ Schuler, R. H., and MeCauley, C. E., J. Amer. Chem. Soc., 79, 821 (1957).

"McCauley, C. E., and Schuler, R. H., J. Phys. Chem., 62, 1364 (1958).

12 Nath, A., Chemical Effects of Nuclear Transformations, 1, 335 (International Atomic Energy Agency, Vienna, 1961). Nath, A., and Nesmeyanov, A. N., Radiokhimiya, 4, 122 (1962) 13 Veljkovic, S. R., and Harbottle, G., BNL-6010 (1962); J. Inorg. Nucl.
Chem., 24, 1517 (1962).

\section{GEOPHYSICS}

\section{Depth of the Mohorovičić-discontinuity under the North Sea Basin}

DuRING this summer and autumn refraction seismic experiments were carried out on the North Sea on a line with azimuth $150^{\circ}$ starting from a position $54^{\circ} 40^{\prime} \mathrm{N}$ and $3^{\circ} 20^{\prime} \mathrm{E}$. The so-called velocity-depth method was adopted in which listening ship and shooting ship are in mirror position with regard to the starting point. In this way the effect of a possible tilt of the layers is eliminated. This has the advantage that no need exists for shooting a reversed profile.

The preliminary results are listed in Table 1.

\begin{tabular}{|c|c|c|}
\hline Veloeity & $\begin{array}{l}\text { Table } 1 \\
\text { Thickness }\end{array}$ & Depth \\
\hline $1.85 \mathrm{~km} / \mathrm{sec}$ & $2 \cdot 2 \mathrm{~km}$ & $40 \mathrm{~m}$ \\
\hline $3.0 \mathrm{~km} / \mathrm{sec}$ & $1.0 \mathrm{~km}$ & 28 \\
\hline $6.15 \mathrm{~km} / \mathrm{sec}$ & $26.5 \mathrm{~km}$ & \\
\hline $8.3 \mathrm{~km} / \mathrm{sec}$ & & \\
\hline
\end{tabular}

The Conrad-discontinuity did not show up in the first arrivals. The heaviest charge was somewhat less than $3,000 \mathrm{~kg}$ TNT at a distance between the ships of $210 \mathrm{~km}$. In all, 46 shots were made. More than half of them had a purely experimental character. In fact, quite a fow charges were fired to find the appropriate charge-distance relation for this region. The experiments were carried out on ships of the Royal Nethorlands Navy. On all the trials H.Neth.M.S. Cerberus acted as the shooting ship. The explosives used were surplus depth charges.

The measurements form part of a larger programme to investigate the relation between sedimentary thickness and the position of tho Moho. This first result seems to 